\title{
MUDANÇAS CLIMÁTICAS E A PRODUÇÃO DE UVA NO VALE DO RIO DO PEIXE-SC ${ }^{1}$
}

\section{ÁLVARO JOSÉ BACK², EMILIO DELLA BRUNA³, MARCO ANTÔNIO DALBÓ ${ }^{4}$}

RESUMO - Foram avaliadas as tendências nas séries climáticas e nos índices agroclimáticos para a cultura da videira no Vale do Rio do Peixe-SC. Foram utilizados os dados diários da Estação Meteorológica de Videira do período de 1971 a 2010. As tendências nas séries foram avaliadas pelo teste de Mann-Kendall, e para estimar a magnitude da tendência utilizou-se a declividade mediana, determinada pelo teste de Theil-Sen. Os resultados mostraram tendência de aumento nas séries de temperatura mínima do ar, em escala anual, bem como nas estações do ano. Para a temperatura máxima do ar, houve tendência significativa de aumento na série de temperatura máxima anual e na temperatura máxima no verão e inverno. Também foi observado aumento da frequência de dias quentes e noites quentes. Com relação aos índices agrometeorológicos, foi observada tendência significativa de diminuição do número de geadas, antecipação das datas de brotação, florescimento e colheita, aumento significativo na soma térmica, no índice de Huglin e no índice de frio. Com relação à precipitação, houve tendência significativa de aumento da precipitação total anual e da precipitação no período de crescimento da cultura da videira e do número de dias com chuva igual ou superior a $20 \mathrm{~mm}$. Termos para indexação: clima, fenologia, videira, índices climáticos.

\section{CLIMATE CHANGES AND GRAPE PRODUCTION IN VALE DO RIO DO PEIXE, IN THE STATE OF SANTA CATARINA}

\begin{abstract}
Trends in climate series and agro-climatic indices were evaluated for growing vines in Vale do Rio do Peixe, in the state of Santa Catarina. Daily data of the Meteorological Station of Videira for the period from 1971 to 2010 were used. The trend in the series was analyzed with the Mann-Kendall test and to estimate the magnitude of the trend it was used the median slope determined by the Theil-Sen estimator. The results showed an increasing trend in series of minimum air temperature at the annual scale and also in the seasons of the year. The maximum air temperature presented a significant trend of increase in the series of annual maximum temperature and in the maximum temperature in summer and winter. It was also observed an increase in frequency of hot days and hot nights. In terms of agrometeorological indices it was observed a significant trend of decrease in the number of frost events, in the reduction of the time of sprouting, flowering and harvesting, and a significant increase in thermal summation, in the Huglin index, and in the cold index. In relation to precipitation there was a significant trend of increase in the annual total precipitation and in precipitation during the period of growth of the vines as well as the number of days with rainfall amounts equal or higher than $20 \mathrm{~mm}$.
\end{abstract}

Index terms: climate, phenology, vine, climate indices.

\footnotetext{
${ }^{1}$ (Trabalho 153-12).Recebido em: 29-11-2012. Aceito para publicação em: 15-05-2012

${ }^{2}$ Eng. Agr., Dr. em Engenharia, Professor do Programa de Pós-Graduação em Ciências Ambientais da Unesc, Pesquisador da Epagri, E-mail: ajb@epagri.sc.gov.br

${ }^{3}$ Eng. Agr. MSc Pesquisador da Epagri/Estação Experimental de Urussanga, Rod. SC 446, km 19, C.P 49, CEP 88840-000, Urussanga SC. E-mail:emilio@epagri.sc.gov.br

${ }^{4}$ Eng. Agr., Ph.D., Epagri/Estação Experimental de Videira, C.P. 21, 89560-000, Videira-SC. E-mail: dalbo@epagri.sc.gov.br
} 


\section{INTRODUÇÃO}

A produção vitícola é uma atividade fortemente influenciada pelo clima, sendo este importante na definição das potencialidades das regiões. A fisiologia da videira é influenciada por diversos elementos meteorológicos, como temperatura, precipitação, déficit de pressão de vapor, evapotranspiração potencial, horas de insolação e vento. Esses fatores meteorológicos interagem com os demais componentes do sistema de produção, assim como o solo, a cultivar e as técnicas agronômicas aplicadas no cultivo, influenciando na produção de uva e na qualidade do vinho.

As modificações climáticas e, em especial, o aumento da temperatura do ar e a modificação da distribuição e da frequências de chuvas podem trazer impactos na produção de uva e na qualidade do vinho, e podem causar modificação na área de cultivo e nas variedades cultivadas (JONES; GOODRICH, 2008).

Extremos de temperatura do ar, tanto mínimas como máximas, podem afetar de modo negativo as culturas agrícolas (STRECK et al. 2007, 2011). As temperaturas extremas acima de $35^{\circ} \mathrm{C}$, registradas no abrigo meteorológico, que corresponde a temperaturas acima de $40^{\circ} \mathrm{C}$ sob o sol, são chamadas temperaturas "negativas" para a videira, porque inibem ou mesmo bloqueiam processos fisiológicos e bioquímicos. As espécies de videiras vão desde as resistentes ao frio ( $V$. labrusca) - Americanas, às sensíveis $V$. rotundifolia, passando pelas parcialmente resistentes ( $V$. vinifera). Todas elas requerem um período de crescimento relativamente quente e longo para a maturação de seus frutos. A videira, como toda a espécie de clima temperado, apresenta um período de repouso vegetativo, quando ocorre a queda gradativa das folhas até o inchamento das gemas, e um período de intensa atividade vegetativa, caracterizada por brotação, floração, frutificação e maturação. A videira não cessa seu crescimento completamente pela não formação de gemas terminais. Os brotos podem aumentar sua velocidade de crescimento em qualquer época, desde que haja calor suficiente e abundância de umidade no solo. Temperatura abaixo de $10^{\circ} \mathrm{C}$ limita o crescimento dos brotos, induzindo desta forma a videira a entrar num período de repouso vegetativo. Assim, a videira exige quantidade de frio de acordo com as diversas cultivares. As cultivares americanas, devido a sua própria origem, são menos exigentes em frio que as europeias. A brotação, a floração, a frutificação e a maturação são fases seguintes do ciclo anual da videira, conhecida como grande fase vegetativa, tendo a temperatura um papel preponderante.
Estudos que envolvem séries temporais longas de elementos meteorológicos são realizadas em diferentes análises, que incluem a determinação de suas tendências (MARENGO et al., 2009; SANSIGOLO; KAYANO, 2010; SANTOS, 2011). Blain (2011), analisando as séries mensais de temperatura máxima e mínima do Estado de São Paulo, conclui que as alterações de ordem climática observadas nas séries de temperatura máxima são bastante inferiores às observadas nas séries de temperatura mínima. Blain e Lulu (2011) não identificaram tendências significativas nas séries de máximas e mínimas absolutas em dados coletados a partir de seis estações meteorológicas distribuídas no Estado de São Paulo. Nemani et al. (2001) afirmam que o aquecimento observado nos anos de 1951 a 1997 determinou alteração generalizada na frequência de geadas, na demanda evaporativa e na duração do ciclo da videira cultivada na Califórnia. Muitas destas modificações climáticas são vistas como vantajosas para a viticultura; no entanto, esses mesmos autores salientam que essas modificações climáticas podem não continuar a ser benéficas para a indústria vinícola da Califórnia devido à possibilidade de aumento de pragas e doenças. Segundo Jones e Goodrich (2008), o aquecimento observado nos últimos 50 anos trouxe benefícios para muitas regiões vitícolas, tal como a redução de geadas. Estes benefícios são mais evidentes nas regiões de climas frios. Por outro lado, nas regiões vitícolas mais quentes e mais secas, houve necessidade de maiores investimentos para a irrigação, aumentando assim os custos de produção.

O excesso hídrico, combinado com temperaturas elevadas, torna a cultura da videira muito suscetível a doenças fúngicas e pragas (BARDIN et al., 2010). Uma seca moderada na maturação favorece a qualidade dos frutos da videira. Segundo Back e Della Bruna (2009), a videira pode ser cultivada sem irrigação a partir de uma precipitação anual de 500 a $600 \mathrm{~mm}$ por ano. Elevada precipitação durante o período de florescimento causa falhas na frutificação durante a maturação, causa apodrecimento dos frutos e perda de qualidade. Segundo Bardin et al. (2010), a aplicação de fungicida após ocorrência de $20 \mathrm{~mm}$ de chuva controlou satisfatoriamente as doenças fúngicas na videira, principalmente a antracnose nos cachos, folhas e ramos, permitindo a redução de aproximadamente $40 \%$ do número total de pulverizações necessárias.

Em Santa Catarina, a vitivinicultura representa uma atividade econômica de considerável importância. A área plantada com videiras no Estado é de 5.060 ha, com uma produção em 
torno de 66.000 toneladas de uva. O Alto Vale do Rio do Peixe, no meio-oeste do Estado, é a região mais tradicional, sendo responsável por mais de dois terços da produção estadual. Os principais municípios produtores são Tangará, Videira, Pinheiro Preto e Caçador. O clima é úmido com verões frescos, predominando os minifúndios, onde os parreirais têm de dois a três hectares em média. As uvas são destinadas à elaboração de vinhos e de sucos, e uma pequena porcentagem vai para o consumo in natura.

O conhecimento dos potenciais impactos da mudança climática na viticultura é necessário para que os pesquisadores e os produtores tomem decisões sobre políticas e práticas de manejo que minimizem os impactos negativos e explorem as possíveis vantagens sobre os impactos positivos. Este trabalho teve como objetivo avaliar as tendências nos dados climáticos e nos índices agroclimáticos relacionados com a viticultura da região do Vale do Rio do Peixe-SC.

\section{MATERIAL E MÉTODOS}

Foram utilizadas as séries históricas diárias de temperatura máxima, mínima e média do ar, do período de 1970 a 2010, registrados na Estação Meteorológica da Empresa de Pesquisa Agropecuária e Extensão Rural de Santa Catarina (Epagri), localizada no município de Videira-SC (latitude $27^{\circ} 00^{\prime} \mathrm{S}$, longitude $51^{\circ} 09^{\prime} \mathrm{W}$, altitude de 779 metros). O clima da região, de acordo com o sistema de classificação climatica de Köppen, é classificado como mesotérmico úmido e verão ameno $(\mathrm{Cfb})$. A temperatura média anual varia de $15,8^{\circ} \mathrm{C}$ a $17,9^{\circ} \mathrm{C}$. A temperatura média máxima varia de $22,3^{\circ} \mathrm{C}$ a $25,8^{\circ} \mathrm{C}$ e a mínima de $10,8^{\circ} \mathrm{C}$ a $12,9^{\circ} \mathrm{C}$. A precipitação pluviométrica anual varia de $1.460 \mathrm{~mm}$ a $1.820 \mathrm{~mm}$, com o total anual de dias de chuva entre 129 e 144 dias (médias normais). Podem ocorrer, em média, de 12 a 22 geadas por ano. O número de horas de frio abaixo ou iguais a $7,2^{\circ} \mathrm{C}$ variam de 437 a 642 horas acumuladas por ano.

Foram calculados os índices climáticos definidos pela Equipe de Especialistas em Detecção, Monitoramento e Índices de Mudanças Climáticas (Expert Team on Climate Change Detection, Monitoring and Índices-ETCCDMI), citados por Back et al. (2012) e também índices agroclimáticos aplicados à videira (Tabela1). Estes índices foram calculados em escala anual, por estação do ano e também na estação de crescimento da cultura da videira, considerado de setembro a fevereiro.

O potencial impacto das mudanças climáticas na viticultura foram detectados pela aplicação de índices agroclimáticos, tais como: número de dias com geada (FD); graus - dia na estação de crescimento (GDD), levando em consideração a data de início das fases fenológicas mais importantes (brotação, florescimento e colheita); a soma térmica com $10^{\circ} \mathrm{C}$ de temperatura basal (setembro a fevereiro) (STA10); o índice de Frio (IF); o índice de Huglin (IH). O IH é usado para a classificação de regiões vitícolas, para caracterizar a adaptação da cultivar às condições climáticas, para a caracterização de terroirs, para monitoramento do desenvolvimento fisiológico e bioquímico da uva, e para a definição do estágio fenológico e data de colheita (TONIETTO ; CARBONNEAU, 2004). O IF pode ser indiretamente relacionado à intensidade do aroma do vinho e à coloração do suco de variedades rosadas, e são considerados bons indicadores da interação entre mudanças no clima e necessidades fisiológicas.

Para a definição das datas de brotação (GDDb), florescimento (GDDf) e colheita (GDDc), foram consideradas as datas em que a soma térmica alcança os respectivos valores de 110;400 e 1.500 graus-dia.

A soma térmica foi calculada como:

$$
\mathrm{STA} 10=\sum_{\mathrm{i}=1}^{\mathrm{n}}(\text { Tmed }-10)
$$

Em que: STA10 é a soma térmica acima da $10^{\circ} \mathrm{C}$ (graus-dia); o Tmed é a temperatura média diária $\left({ }^{\circ} \mathrm{C}\right)$, calculada como:

$$
\text { Tmed }=\frac{T x+T n}{2}
$$

Em que: Tx é a temperatura máxima diária $\left({ }^{\circ} \mathrm{C}\right)$; Tn é a temperatura mínima diária $\left({ }^{\circ} \mathrm{C}\right)$.

O Índice de Huglin foi calculado segundo a fórmula:

$$
\mathrm{HI}=\sum \frac{(\text { Tmed }-\mathrm{T})+(\mathrm{Tx}-\mathrm{Tb})}{2}
$$

Em que: Hi é o índice de Huglin $\left({ }^{\circ} \mathrm{C}\right)$;

$\mathrm{Tb}$ é a temperatura de base $\left(10^{\circ} \mathrm{C}\right)$;

$\mathrm{k}$ é um coeficiente multiplicador, que para a latitude de região em estudo $\mathrm{k}=1$ (BORGHEZAN et al., 2011).

Com relação à precipitação, foram considerados os índices de precipitação total anual (PRa), precipitação na estação de crescimento (PRec) e o número de dias de chuva superior a $20 \mathrm{~mm}$ (R20). Nos cálculos destes índices, somente foram consideradas as chuvas iguais ou superiores a 1,0 $\mathrm{mm}$.

Para avaliar a tendência de mudanças climá- 
ticas, foi utilizado o teste não paramétrico de Mann-Kendall. Segundo Burn et al. (2004), as hipóteses a serem testadas são: H0.Os dados são uma amostra de uma variável aleatória de $\mathrm{n}$ dados independentes e identicamente distribuídos (isto é, não existe tendência no conjunto de dados).

H1: A distribuição dos dados $x_{\mathrm{i}}$ e $\mathrm{x}_{\mathrm{j}}$ não é idêntica para todos $\mathrm{i}, \mathrm{j} \leq \mathrm{N}$, em que i e $\mathrm{j}$ são as sequências dos dados e $\mathrm{N}$ é o comprimento da série.

Na estatística Mann-Kendall, S é dado por

$$
\mathrm{S}=\sum_{\mathrm{j}=1}^{\mathrm{N}-1} \sum_{\mathrm{i}=\mathrm{j}+1}^{\mathrm{N}} \operatorname{sgn}\left(\mathrm{x}_{\mathrm{i}}-\mathrm{x}_{\mathrm{j}}\right)
$$

em que:

$$
\operatorname{sgn}(\theta) \quad\left\{\begin{array}{r}
1 \operatorname{se} \theta>0 \\
0 \operatorname{se} \theta=0 \\
-1 \operatorname{se} \theta<0
\end{array}\right\}
$$

Para variável aleatória independente distribuída identicamente (sem tendência), a média e a variância de $\mathrm{S}$ são dadas por:

$$
\mathrm{E}(\mathrm{S})=0
$$

$$
\operatorname{Var}(\mathrm{S})=\frac{\mathrm{N}(\mathrm{N}-1)(2 \mathrm{~N}+5)-\Sigma_{\mathrm{t}}^{\mathrm{N}}(\mathrm{t}-1)(2 \mathrm{t}+5)}{18}
$$

Em que: $\mathrm{t}=$ extensão a qualquer empate.

Para o teste bicaudal, ao nível de significância $\alpha$, rejeita-se Ho se o teste estatístico padronizado, $Z$ $<Z_{\alpha / 2}$ ou $Z>Z_{\alpha / 2}$, em que a estatística normalizada $Z$ de Mann-Kendall segue a distribuição normal, com média zero e variância um. $\mathrm{O}$ valor de $\mathrm{Z}$ é calculado por:

$$
Z=\left\{\begin{array}{cc}
\frac{S-1}{\sqrt{\operatorname{var}(S)}} & \text { se } S>0 \\
0 & \text { se } S=0 \\
\frac{S+1}{\sqrt{\operatorname{var}(S)}} & \text { se } S<0
\end{array}\right\}
$$

O teste de Mann-Kendall não fornece estimativa da magnitude da tendência. Para obter esta estimativa, foi utilizado o teste não paramétrico de Theil-Sen, em que a estimativa robusta da inclinação ( $\beta)$ é obtida por:

$$
\boldsymbol{\beta}=\operatorname{mediana}\left(\frac{\mathbf{y}_{\mathrm{j}}-\mathbf{Y}_{\mathbf{i}}}{\mathbf{t}_{\mathrm{j}}-\mathbf{t}_{\mathrm{i}}}\right) \text {, para todos } \mathrm{i}>\mathrm{j} \text {. }
$$

Em que : Y é a variável testada para tendência e t é o tempo; $\beta$ representa a mediana da inclinação obtida de todas as possíveis combinações de dois pontos da série temporal.

\section{RESULTADOS E DISCUSSÃO}

Na Tabela 2, constam os valores de " $Z$ " do teste de Mann-Kendall com a respectiva significância (valor "p"). Também consta a declividade mediana $(\beta)$ com os respectivos intervalos de confiança obtidos pelo teste Theil-Sen. Todos os índices de temperatura mínima apresentaram tendência significativa de aumento. A temperatura mínima anual (TNa), com mediana de $12,1^{\circ} \mathrm{C}$, apresenta inclinação mediana $(\beta)$ de $0,0471^{\circ} \mathrm{C} /$ ano, o que indica aumento aproximado de $4,7^{\circ} \mathrm{C} /$ século (Figura 1A). Maiores aumentos são verificados na primavera $(\mathrm{TNp})\left(\beta=0,0528^{\circ} \mathrm{C} / \mathrm{ano}\right)$ e outono (TNo) $\left(\beta=0,0493^{\circ} \mathrm{C} / \mathrm{ano}\right)$.

Com relação aos dados de temperatura máxima, foi verificado tendência significativa para a média da temperatura máxima anual (TXa) (Figura 1B) $\left(\beta=0,0346^{\circ} \mathrm{C} / \mathrm{ano}\right)$. Analisando os dados de temperatura máxima nas estações do ano, foi constatado tendência significativa de aumento nas médias somente para as médias nas estações do verão (TXv) (Figura $1 \mathrm{C}$ ) e inverno (TNi) $\left(\beta=0,0302^{\circ} \mathrm{C} /\right.$ ano e $\beta=0,0314^{\circ} \mathrm{C} / \mathrm{ano}$, respectivamente).

$\mathrm{O}$ número de noites quentes (TN90p) apresentou tendência significativa de aumento, com declividade mediana $(\beta)$ de 0,2857 dia/ano (Figura 1D), o que equivale ao aumento de 2,8 noites quentes a cada dez anos. Também foi observado aumento significativo da frequência de dias quentes (Figura $1 \mathrm{E})$, representada pela frequência de temperaturas máximas acima do percentil 90 (TX90p). As temperaturas extremas acima de $35^{\circ} \mathrm{C}$ registradas no abrigo meteorológico, e que corresponde a temperaturas acima de $40^{\circ}$ sub o sol, são chamadas temperaturas "negativas" para a videira, porque inibem ou mesmo bloqueiam processos fisiológicos e bioquímicos.

O aumento na temperatura mínima é responsável pelo aumento na temperatura média, e como consequência no aumento da soma térmica. Segundo Nemani et al. (2001), o aquecimento global tem como consequência o aumento da evaporação e conteúdo de vapor na atmosfera, aumento da nebulosidade e de chuvas. Os resultados obtidos no presente trabalho estão de acordo vários estudos realizados na região Sul do Brasil (MARENGO; CAMARGO, 2008; KAYANO ;SANSIGOLO, 2009; BLAIN et al., 2009; SANSIGOLO; KAYANO, 2010). Com o aumento da temperatura mínima, ocorre diminuição da frequência de geadas, aumento da estação de crescimento livre de geadas, fatores considerados como vantagens para a viticultura.

O número de geadas por ano (FD), com valor da mediana de 20 geadas anuais, apresentou tendência 
significativa de diminuição, com declividade $(\beta=$ -0,40 geadas/ano), o que indica a diminuição de 4 dias com geada a cada década (Figura 1F).

Dessa forma, pode-se observar que, de modo geral, há um aumento nas temperaturas máximas somente no verão e inverno. Para as temperaturas mínimas, o aumento foi significativo em todas as estações do ano, que determina como consequência aumento das temperaturas médias e diminuição do número de geadas, aumento da frequência de dias e noites quentes.

Com relação à duração das fases fenológicas, foi identificada tendência significativa de antecipação das datas da brotação (GDDb), florescimento (GDDf) e colheita (GDDc) com declividade $(\beta)$ mediana de -0,298 dia/ano, -0,333 dia/ano -0,588 dia/ano, respectivamente. Dessa forma, conclui-se que as alterações climáticas estão antecipando as fases fenológicas e a data da colheita da videira (Figura 2A).

$\mathrm{O}$ índice de Huglin (HI) mostrou tendência de aumento com declividade $(\beta)$ mediana de $6,5^{\circ} \mathrm{C}$ dia/ano (Figura 2B). Este índice tem considerável implicação para a viticultura, pois as temperatura noturnas são importantes para o desenvolvimento do aroma do fruto, e do $\mathrm{pH}$ do suco em termos de degradação do ácido málico sob condições de elevadas temperaturas.

O índice de frio (IF) é utilizado como indicador das condições de temperatura noturna durante a maturação (CONCEIÇÃO; TONIETTO, 2005). Os dados apontam que o índice de frio mediano foi de $17,1^{\circ} \mathrm{C}$, com tendência significativa de aumento $\left(\beta=0,03^{\circ} \mathrm{C} /\right.$ ano $)$ (Figura $2 \mathrm{C}$ ). De acordo com Conceição e Tonietto (2005), o valor de IF de $17,1^{\circ} \mathrm{C}$ caracteriza a região como classe "de noites temperadas $(14<\mathrm{IF} \leq 18)$ ", mas com a tendência de aumento poderá passar para a classe "de noites quentes IF > 18".

A soma térmica mostrou tendência de aumento com declividade mediana de $8,8287^{\circ} \mathrm{C} \mathrm{dia/}$ ano (Figura 2D), o que justifica a antecipação das fases fenológicas. A temperatura afeta a qualidade do vinho. Um local com dias quentes e noites quentes produz vinho com estilo diferente, na comparação com uma região ainda com a mesma soma térmica, mas com dias quentes e noites frias. Quando temperaturas noturnas se aproximam de $10^{\circ} \mathrm{C}$, a baga cessa a maturação. Quando a temperatura noturna eleva-se acima daquele patamar, a maturação continua durante a noite. Assumindose que a temperatura diurna se aproxima do ótimo para maturação, a menor amplitude térmica diária produz a maturação mais rápida que locais com maior amplitude térmica diária. Na prática, para uma determinada variedade, microclimas com menor amplitude térmica diária geralmente maturam o fruto com maior teor de sacarose, na comparação com locais onde ocorrem maior amplitude térmica e maiores índices de nebulosidade e com similar soma térmica.

Com relação à precipitação, os índices mostraram aumento significativo na chuva anual ( $\beta$ $=12,37 \mathrm{~mm} / \mathrm{ano}$ ) e na chuva durante a estação de crescimento ( $\beta=10,21 \mathrm{~mm} / \mathrm{ano}$ ) (Figura $2 \mathrm{E}$ ). Com relação aos dias de chuva acima e $20 \mathrm{~mm}$ (R20), observa-se tendência de aumento $(\beta=0,28$ chuva/ ano) (Figura $2 \mathrm{~F}$ ). $\mathrm{O}$ excesso hídrico combinado com temperaturas elevadas torna a cultura da videira muito suscetível a doenças fúngicas e pragas (BARDIN et al., 2010). Segundo Back e Della Bruna (2009), a videira pode ser cultivada sem irrigação a partir de uma precipitação anual de 500 a 600 $\mathrm{mm}$. A precipitação mediana durante a estação de crescimento foi de $1.006,9 \mathrm{~mm}$, indicando que, em geral, há excesso de precipitação na região de Videira. A constatação de tendência de aumento da chuva anual, bem como da chuva durante o período vegetativo, implica preocupação com relação à qualidade da uva e dificuldade na realização dos tratos culturais. Espera-se maior incidência de doenças pelo aumento da chuva. Dessa forma, podese inferir pelo índice R20, no período vegetativo, um aumento do número de pulverizações contra doenças fúngicas, com consequência de aumento dos custos e diminuição da qualidade dos frutos. 
TABELA 1- Índices climáticos e agroclimáticos usados e suas definições.

\begin{tabular}{|c|c|c|}
\hline \multicolumn{2}{|c|}{ Índice unidade } & \multirow{2}{*}{ Média da Temperatura mínima anual } \\
\hline $\mathrm{TNa}$ & ${ }^{\circ} \mathrm{C}$ & \\
\hline $\mathrm{TNp}$ & ${ }^{\circ} \mathrm{C}$ & Média da Temperatura mínima diária na primavera \\
\hline $\mathrm{TNv}$ & ${ }^{\circ} \mathrm{C}$ & Média da Temperatura mínima diária no verão. \\
\hline TNo & ${ }^{\circ} \mathrm{C}$ & Média da Temperatura mínima diária no outono \\
\hline $\mathrm{TNi}$ & ${ }^{\circ} \mathrm{C}$ & Média da Temperatura mínima diária no inverno \\
\hline $\mathrm{TXa}$ & ${ }^{\circ} \mathrm{C}$ & Média da Temperatura máxima anual \\
\hline TXp & ${ }^{\circ} \mathrm{C}$ & Média da Temperatura máxima diária na primavera \\
\hline TXv & ${ }^{\circ} \mathrm{C}$ & Média da Temperatura máxima diária no verão \\
\hline TXo & ${ }^{\circ} \mathrm{C}$ & Média da Temperatura máxima diária no outono \\
\hline TXi & ${ }^{\circ} \mathrm{C}$ & Média da Temperatura máxima diária no inverno \\
\hline TN90p & & $\begin{array}{l}\text { Número de dias com temperatura mínima acima do percentil } 90 \text { (1961-1990) calculado no } \\
\text { período de verão }\end{array}$ \\
\hline TX90p & & $\begin{array}{l}\text { Número de dias com temperatura máxima acima do percentil } 90 \text { (1961-1990) calculado no } \\
\text { período de verão }\end{array}$ \\
\hline FD & dias & Número de dias do ano com temperatura mínima abaixo de $0^{\circ} \mathrm{C}$ \\
\hline GDDb & dias & $\begin{array}{l}\text { Data da brotação; é o dia do ano quando a soma da diferença entre a temperatura média } \\
\text { diária e a temperatura base }\left(10^{\circ} \mathrm{C}\right) \text { alcança o valor específico. }\end{array}$ \\
\hline GDDf & dias & $\begin{array}{l}\text { Data do florescimento; é o dia do ano quando a soma da diferença entre a temperatura média } \\
\text { diária e a temperatura base }\left(10^{\circ} \mathrm{C}\right) \text { alcança o valor específico. }\end{array}$ \\
\hline GDDc & dias & $\begin{array}{l}\text { Data da colheita; é o dia do ano quando a soma da diferença entre a temperatura média } \\
\text { diária e a temperatura base }\left(10^{\circ} \mathrm{C}\right) \text { alcança o valor específico. }\end{array}$ \\
\hline HI & graus & $\begin{array}{l}\text { Índice Huglin: soma diária da média entre a temperatura máxima e a média calculada durante } \\
\text { a estação de crescimento (março a setembro) multiplicado pelo coeficiente de latitude }\end{array}$ \\
\hline IF & ${ }^{\circ} \mathrm{C}$ & $\begin{array}{l}\text { Índice de frio representado pela temperatura mínima do mês antecedente à colheita } \\
\text { (Fevereiro) }\end{array}$ \\
\hline STA10 & ${ }^{\circ} \mathrm{C}$ & $\begin{array}{l}\text { Soma térmica (temperatura base } 10^{\circ} \mathrm{C} \text { ): soma da temperatura média diária no período de } \\
\text { crescimento (setembro a fevereiro) }\end{array}$ \\
\hline $\mathrm{PRa}$ & $\mathrm{mm}$ & Precipitação total anual \\
\hline PRp & $\mathrm{mm}$ & Precipitação total durante a primavera \\
\hline PRv & $\mathrm{mm}$ & Precipitação total durante o verão \\
\hline PRo & $\mathrm{mm}$ & Precipitação total durante o outono \\
\hline PRi & $\mathrm{mm}$ & Precipitação total durante o inverno \\
\hline PRec & $\mathrm{mm}$ & Precipitação total durante a estação de crescimento \\
\hline $\mathrm{R} 20$ & $\mathrm{~N}^{\circ}$ & Número de dias no ano com chuva superior a $20 \mathrm{~mm}$ \\
\hline
\end{tabular}


TABELA 2- Resultados dos testes estatísticos da tendência dos índices climáticos aplicados ao cultivo da videira em Videira-SC.

\begin{tabular}{|c|c|c|c|c|c|c|c|}
\hline \multirow[b]{2}{*}{ índice } & \multicolumn{3}{|c|}{ Teste Mann-Kendal } & \multicolumn{4}{|c|}{ Teste Theil-Sen } \\
\hline & $\mathrm{S}$ & Z & $\mathrm{p}$ values & mediana & $\beta$ & $\beta$ inferior & $\beta$ superior \\
\hline $\mathrm{TNa}$ & 415 & 4,650 & $<0,0001$ & 12,1 & 0,0471 & 0,0633 & 0,0300 \\
\hline $\mathrm{TNp}$ & 309 & 3,459 & 0,0005 & 12,2 & 0,0528 & 0,0813 & 0,0273 \\
\hline $\mathrm{TNv}$ & 265 & 2,965 & 0,0030 & 16,6 & 0,0364 & 0,0573 & 0,0167 \\
\hline TNo & 248 & 2,774 & 0,0055 & 12,3 & 0,0493 & 0,0767 & 0,0135 \\
\hline $\mathrm{TNi}$ & 167 & 1,865 & 0,0622 & 7,4 & 0,0333 & 0,0600 & 0,0000 \\
\hline TXa & 348 & 3,897 & 0,0001 & 24,8 & 0,0346 & 0,0500 & 0,0191 \\
\hline TXo & 176 & 1,397 & 0,1625 & 24,8 & 0,0247 & 0,0513 & 0,0000 \\
\hline $\mathrm{TXv}$ & 261 & 2,920 & 0,0035 & 28,3 & 0,0302 & 0,0500 & 0,0116 \\
\hline TXo & 173 & 1,932 & 0,0534 & 24,5 & 0,0234 & 0,0513 & 0,0000 \\
\hline TXi & 203 & 2,269 & 0,0233 & 20,8 & 0,0314 & 0,0594 & 0,0056 \\
\hline TX90 & 183 & 2,044 & 0,0410 & 24,0 & 0,2857 & 0,5647 & 0,0000 \\
\hline TX90 & 223 & 2,493 & 0,0127 & 30,0 & 0,4737 & 0,8000 & 0,0930 \\
\hline STA10 & 389 & 4,358 & $<0,0001$ & 2578,9 & 8,8287 & 12,0350 & 5,4581 \\
\hline GDDb & -323 & $-3,617$ & 0,0003 & 248 & $-0,2986$ & $-0,1533$ & $-0,4211$ \\
\hline GDDf & -326 & $-3,650$ & 0,0003 & 289 & $-0,3333$ & $-0,1818$ & $-0,4628$ \\
\hline GDDc & -514 & $-5,762$ & $<0,0001$ & 22 & $-0,5880$ & $-0,4433$ & $-0,750$ \\
\hline HI & 341 & 3,819 & 0,0001 & 4802,8 & 6,5221 & 8,6518 & 3,7180 \\
\hline FD & -322 & $-3,605$ & 0,0003 & 20,0 & $-0,4000$ & $-0,2066$ & $-0,6340$ \\
\hline IF & 197 & 2,201 & 0,0277 & 17,1 & 0,0333 & 0,0641 & 0,0049 \\
\hline PRa & 187 & 2,250 & 0,0244 & 1775,7 & 12,3667 & 22,9680 & 1,0183 \\
\hline R20 & 203 & 2,444 & 0,0145 & 29,0 & 0,2857 & 0,5000 & 0,0714 \\
\hline PRec & 251 & 3,143 & 0,0017 & 1006,9 & 10,2100 & 16,7618 & 4,1660 \\
\hline
\end{tabular}




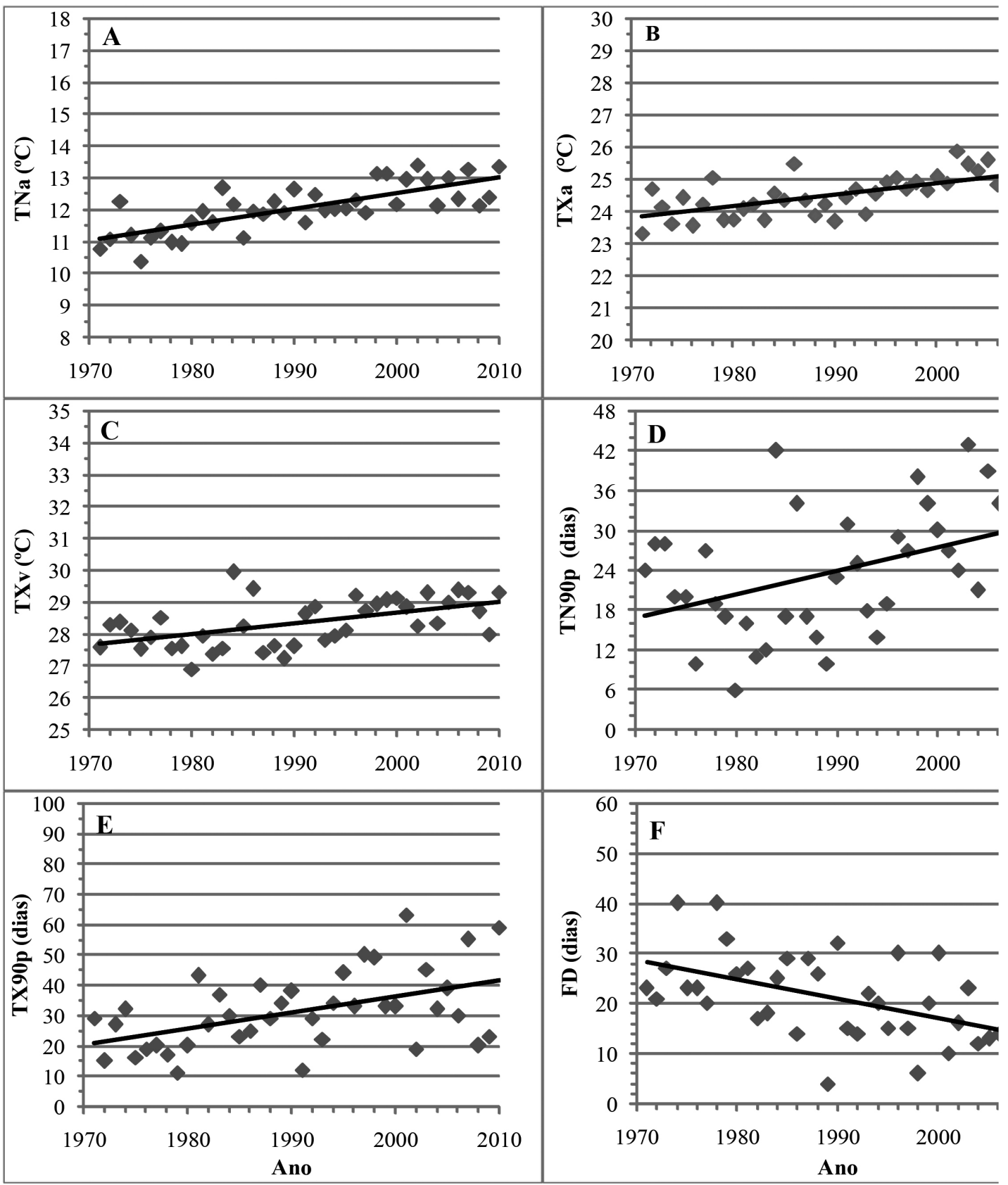

FIGURA 1- Tendência dos índices TNa (A); TXa (B); TXv (C), TN90p (D), TX90p (E), FD (F) para Videira-SC. 

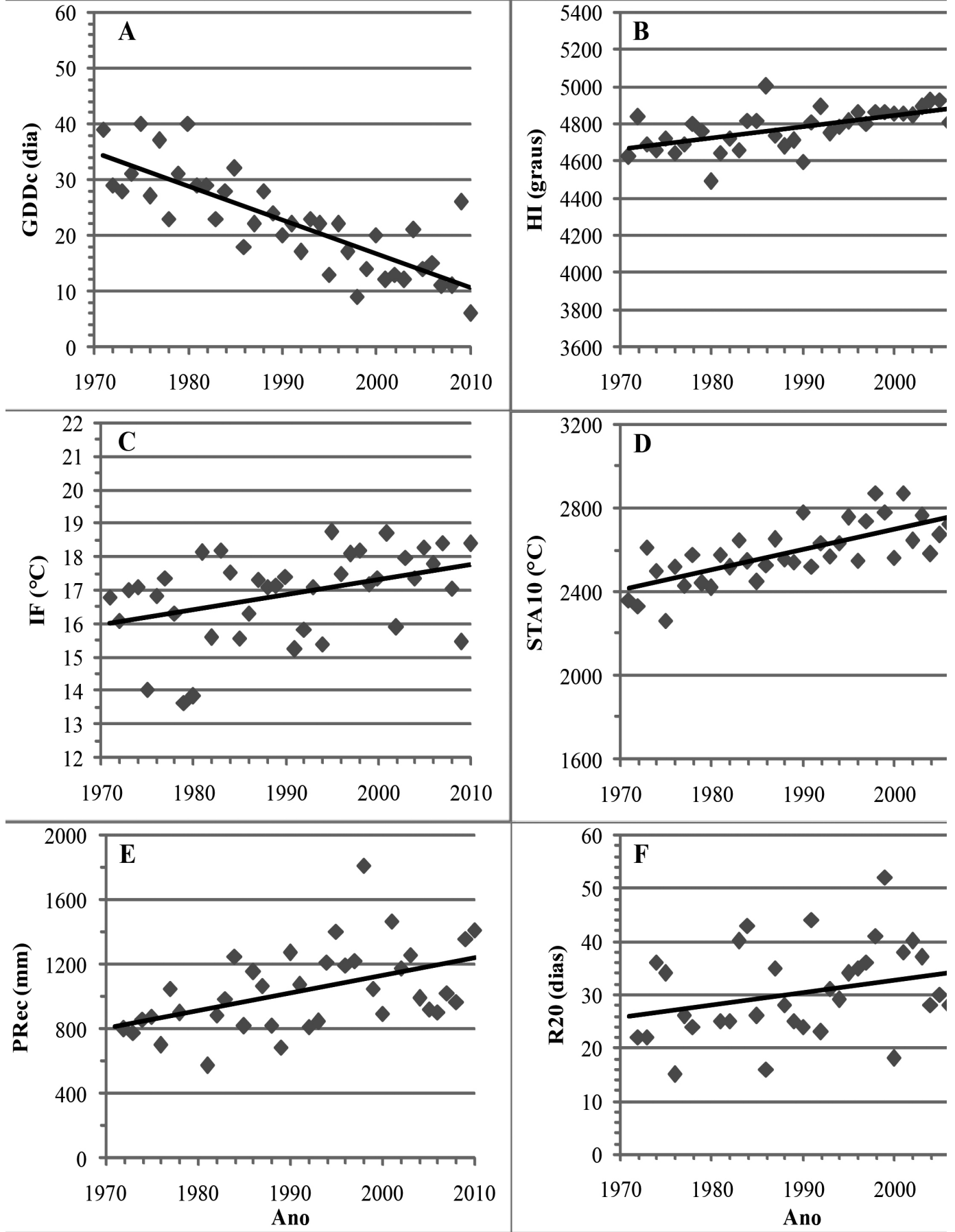

FIGURA 2- Tendência dos índices GDDc (A); HI (B); IF (C), STA10 (D), PRec (E), R20 (F) para Videira-SC. 


\section{CONCLUSÕES}

1- Há tendência de aumento na temperatura mínima anual bem como da temperatura mínima durante o ano todo.

2- A temperatura máxima anual apresenta tendência significativa de aumento na média anual, como também no verão e inverno.

3-São observados tendência de diminuição do número de geadas, aumento da soma térmica, aumento do índice de Huglin e antecipação das datas de brotação, florescimento e colheita.

4- São observados tendência de aumento da chuva total anual, bem como da chuva na estação de crescimento e o período vegetativo, e do número de dias de chuva acima de $20 \mathrm{~mm}$.

\section{REFERÊNCIAS}

BACK, Á.J.; DELLA BRUNA, E.; VIEIRA, H.J. Tendências climáticas e produção de uva na região dos Vales da Uva Goethe. Pesquisa Agropecuária Brasileira, Brasília, v.47, n.4, p.497-504, 2012.

BACK, Á.J.; DELLA BRUNA, E. Demanda hídrica e necessidade de irrigação da videira para Urussanga, SC. Agropecuária Catarinense, Florianópolis, v.22, p.76-81, 2009.

BARDIN, L.; PEDRO JUNIRO, M.J.; MORAES, J. F.L. Risco climático de ocorrência de doenças fúngicas na videira Niagara Rosada na região do pólo turístico do circuito das frutas do Estado de São Paulo. Bragantia, Campinas, v.69, n.4, p.10191026, 2010

BLAIN, G.C. Considerações estatísticas relativas a seis séries mensais de temperatura do ar da Secretaria de Agricultura e Abastecimento do Estado de São Paulo. Revista Brasileira de Meteorologia, São José dos Campos, v.26, n.2, p.279-296, 2011.

BLAIN, G.C; LULU, J. Valores anuais absolutas de séries de temperatura máxima e mínima do ar no Estado de São Paulo: Tendências, periodicidades e probabilidades associadas. Revista Brasileira de Meteorologia, São José dos Campos, v.26, n., p.29-40, 2011.
BLAIN, G.C.; PICOLE, M.C.A.; LULU, J. Análises estatísticas das tendências de elevação nas séries de temperatura mínima do ar no Estado de São Paulo. Bragantia, Campinas, v.68, n.3, p.807-815, 2009.

BORGHEZAN, M.; GAVIOLI, O.; PIT, F.A.; SILCA, A.L. da. Comportamento vegetativo e produtivo da videira e composição da uva em São Joaquim, Santa Catarina. Pesquisa Agropecuária Brasileira, Brasília, v.46, n.4, p.398-405, 2011.

BURN, D. H.; CUNDERLIK, J. M.; PIETRONIRO, A. Hydrological trends and variability in the Liard River Basin. Hydrological Sciences Journal, Oxford, v.49, n.1, p.53-68, 2004.

CONCEIÇÃO, M.A.F.; TONIETTO, J. Climatic potential for wine grape production in the tropical north region of Minas Gerais State, Brazil. Revista Brasileira de Fruticultura, Jaboticabal, v.37, n.3, p.404-407, 2005.

JONES, G.V.; GOODRICH, G.B. Influence of climate variability on wine regions in The western USA and on wine quality in the Napa Valley. Climate Research, Oldendorf v.35, n.3, p.241-254. 2008.

KAYANO, M.T.; SANSIGOLO, C. Interannual to decadal variations of precipitation and daily maximum and minimum temperature in Southern Brazil. Theoretical and Applied Climatology, Wien, v.97, n.1-2, p.81-90, 2009.

MARENGO, J.A.; CAMARGO, C.C. Surface air temperature trends in Southern Brazil for 1960-2002. International. Journal of Climatology, Chichester, v.28, p.893-904, 2008.

MARENGO, J.A.; JONES, R.; ALVES, L.M.; VALVERDE, M.C. Future change of temperature and precipitation extremes in South America derived from PRECIS regional climate modeling system. International Journal of Climatology, Chichester. v.29, p.2241-2255, 2009.

NEMANI, R. R.; WHITE, M.A.; CAYAN, D.R.; JONES, G.V.; RUNNING, S.W.; COUGHLAN, J.C.; PETERSON, D.L. Asymmetric warming over coastal California and its impact on the premium wine industry. Climate Research, Oldendorf, v.19, n.2, p.25-34, 2001 
SANSIGOLO, C.A.; KAYANO, M.T. Trends of seasonal maximum and minimum temperatures and precipitations in Southern Brazil for de 1913-2006 period. Theoretical and Applied Climatology, Wien, v.101, n.1-2, p.209-206, 2010.

SANTOS, C.A.C. Trends in indices for extremes in daily air temperature over Utah, USA. Revista Brasileira de Meteorologia, São José dos Campos, v.26, n.1, p.19-28, 2011.

STRECK, N.A.; GABRIEL, L.F.; BURIOL, G.A.; HEDWEIN, A.B. PAULA, G.M. Variabilidade interdecadal na série secular de temperatura do ar em Santa Maria, RS. Pesquisa Agropecuária Brasileira, Brasília, v.46, n.8, p.781-790, 2011.
STRECK, N.A. PAULA, F.L.M. DE ; BISOGNIN, D.A.; HELDWEIN, A. B.; DELLAI, J. Simulating the development of field-grown potato (Solanum tuberosum L.). Agricultural and Forest Meteorology, Amsterdam, v.141, p.1-11, 2007.

TONIETTO, J.; CARBONNEAU, A. A multicriteria climatic classification system for grape-growing regions worldwide. Agricultural and Forest Meteorology, Amsterdam, v.124, n.1-2, p.81-97, 2004. 